\title{
Esophageal Mixed Adenoneuroendocrine Carcinoma
}

National Cancer Institute

\section{Source}

National Cancer Institute. Esophageal Mixed Adenoneuroendocrine Carcinoma. NCI

Thesaurus. Code C95621.

A carcinoma that arises from the esophagus and is characterized by the presence of a malignant glandular epithelial component and a malignant neuroendocrine component. At least 30 percent of either component should be present for the diagnosis to be made. 